Research Article

\title{
Fundamental Properties of Magnesium Phosphate Cement Mortar for Rapid Repair of Concrete
}

\author{
Joon Woo Park, Ki Hwan Kim, and Ki Yong Ann \\ Department of Civil and Environmental Engineering, Hanyang University, Ansan 15588, Republic of Korea \\ Correspondence should be addressed to Ki Yong Ann; kann@hanyang.ac.kr
}

Received 17 June 2016; Revised 23 August 2016; Accepted 30 August 2016

Academic Editor: Robert Cerný

Copyright (C) 2016 Joon Woo Park et al. This is an open access article distributed under the Creative Commons Attribution License, which permits unrestricted use, distribution, and reproduction in any medium, provided the original work is properly cited.

\begin{abstract}
Fundamental properties of magnesium phosphate cement (MPC) were investigated in this paper. The setting time and compressive and bond (i.e., flexural and tensile bond) strengths were measured to assess the applicability, and hydration product was detected by the X-ray diffraction. The specimens were manufactured with magnesia and potassium dihydrogen phosphate $\left(\mathrm{K}_{2} \mathrm{HPO}_{4}\right)$ was added to activate hydration process. The Borax $\left(\mathrm{Na}_{2} \mathrm{~B}_{4} \mathrm{O}_{7} \cdot 10 \mathrm{H}_{2} \mathrm{O}\right)$ was used as a retarder to mitigate overwhelming rapid hardening. Mercury intrusion porosimetry was used to examine the pore structure of MPC mortar, and simultaneously rapid chloride penetration test was performed. As a result, the compressive strength of MPC mortar was mostly achieved within 12 hours; in particular, the MPC mortar at 4.0 of M/P ranked the highest value accounting for $30.0 \mathrm{MPa}$. When it comes to tensile and flexural bond to old substrate in mortar patching, the MPS had the higher tensile and flexural strengths, accounting for 1.9 and 1.7 MPa, respectively, compared to OPC mortar patching. Unlike Portland cement mortar, the MPC mortar contained mainly air void rather than capillary pores in the pore distribution. Presumably due to reduced capillary pore in the MPC, the MPC indicated lower penetrability in the chloride penetration test.
\end{abstract}

\section{Introduction}

Concrete structure may often suffer from an unexpected deterioration in terms of pop-out arising from physical/chemical delamination and corrosion of steel reinforcement. Moreover, internal cracking has still a potential risk of degradation of concrete properties, subsequently leading to structural failure $[1,2]$. Thus, regular repair and rehabilitation would be required to secure a structural safety. However, unlike other civil infrastructures, the traffic restriction during the repair of pavement costs high; only a couple of hours are given for the repair treatment at night to avoid congestion of transportation. Additionally, the conventional repair materials such as ordinary Portland cement and hot-mix asphalt may face early degradation due to a debondment from the existing substrate [3-6].

A recent study reported that magnesium phosphate cement (MPC) can rapidly harden to gain the strength in a short duration, ranging about several hours to the level of normal strength of ordinary Portland cement concrete $[7,8]$.
Typically used MPC was produced by using ammonium phosphate $[9,10]$. However, ammonium gas is generated during hydration product and this causes serious odour. Due to its disadvantage, many researchers have effort on finding other phosphate slat. As a result, they found potassium dihydrogen phosphate $\left(\mathrm{KH}_{2} \mathrm{PO}_{4}\right)$ as a replacement. Further studies on MPC using potassium dihydrogen phosphate showed that it has high bond strength [11, 12] and low drying shrinkage [13]. However, limited investigation has been conducted on applying MPC for repair of concrete pavement.

In present study, to verify the feasibility of the MPC as a repair mortar to concrete pavement, the setting time was measured by a monitoring of the penetration resistance to fresh mortar, and simultaneously a development of the strength was evaluated. To evaluate its properties with old substrate, bond strength was performed. Additionally the pore structure of MPC mortar was examined by mercury intrusion porosimetry to explain the relation between the porosity and mechanical properties and also explain the relation between pore distribution and ionic permeability. 
TABLE 1: Chemical composition of magnesia and ordinary Portland cement.

\begin{tabular}{lcccccccc}
\hline \multirow{2}{*}{ Binder type } & \multicolumn{4}{c}{ Oxide composition (\%) } & \multicolumn{2}{c}{ Ignition loss $(\%)$} & Fineness $\left(\mathrm{cm}^{2} / \mathrm{g}\right)$ \\
\hline Magnesia $(\mathrm{MgO})$ & $\mathrm{CaO}$ & $\mathrm{SiO}_{2}$ & $\mathrm{Al}_{2} \mathrm{O}_{3}$ & $\mathrm{Fe}_{2} \mathrm{O}_{3}$ & $\mathrm{MgO}$ & $\mathrm{SO}_{3}$ & & 5089 \\
OPC & 4.1 & 3.3 & 0.5 & 2.2 & 88.5 & 0.1 & - & 2.1 \\
\hline
\end{tabular}

TABLE 2: Mix proportion of MPC paste/mortar.

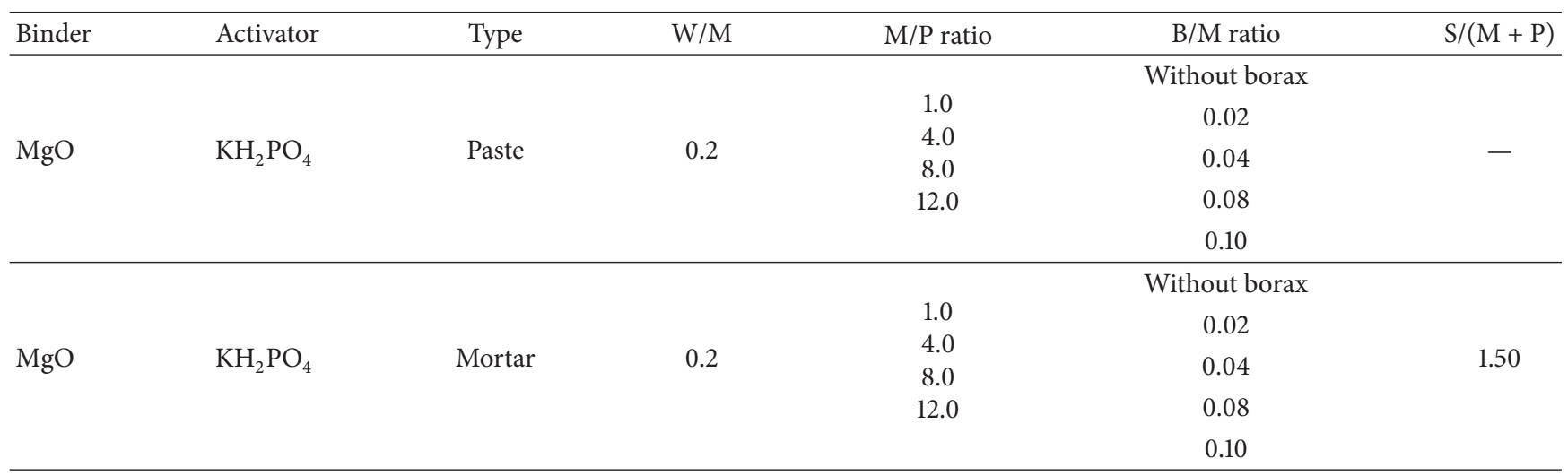

\section{Experimental Works}

2.1. Materials and Specimen Preparation. To assess the mechanical properties of magnesium phosphate cement (MPC) mortar, magnesia was used as a binder, while ordinary Portland cement (OPC) was used for the control. The oxide composition of binders was measured by X-ray fluorescence as given in Table 1 . The fineness of magnesia and OPC was 5,089 and $3,120 \mathrm{~cm}^{2} / \mathrm{g}$, respectively. To activate the hydration process in MPC matrix, potassium dihydrogen phosphate was admixed. The purity of $\mathrm{MgO}$ exceeded $88.5 \%$ and $\mathrm{KH}_{2} \mathrm{PO}_{4}$ exceeded $99.8 \%$. MPC paste specimens were cast for a measurement of X-ray diffraction (XRD) analysis. Mix proportion for MPC paste was varied with $\mathrm{MgO} /$ phosphate $(\mathrm{M} / \mathrm{P})$ ratio and borax/MgO $(\mathrm{B} / \mathrm{M})$ and water/MgO $(\mathrm{W} / \mathrm{M})$ was 0.20 (Table 2 ). To observe the hydration product of MPC, $\mathrm{M} / \mathrm{P}$ of $4, \mathrm{~B} / \mathrm{M}$ of 0.08 , and $\mathrm{W} / \mathrm{M}$ of 0.20 were used. MPC mortar specimens were cast for a measurement of mechanical properties (setting time, compressive strength, tensile/flexural bond strength) and pore structures.

2.2. Testing for Development of MPC. The setting time was determined by the penetration resistance of fresh mortar, measuring periodically its behavior with vicat needles. The initial setting time was determined when penetration depth reached to $25 \mathrm{~mm}$ and the final setting time was determined when needle does not mark the specimen surface with a complete circular impression. The size of needle was $50 \mathrm{~mm}$ height and $1 \mathrm{~mm}$ diameter. The mortar specimen was used in this experiment and the cylinder rubber mould sized $\phi 80 \times$ $40 \mathrm{~mm}$ was used. Simultaneously the compressive strength of MPC mortar was measured, using a cubic specimen $(50 \times$ $50 \times 50 \mathrm{~mm})$ at 1-, 3-, 12-, and 24-hour and 28-day curing. The specimen was wrapped to cure at $25^{\circ} \mathrm{C}$ in a polythene film, immediately after demoulding to avoid leaching-out of ions. The replication of each measurement was 3 and their average value was taken as the value of strength. When it comes to bond strength, tensile and flexural bond strength was simultaneously measured. For the flexural bond strength, the margin of MPC mortar was $50 \times 200 \times 400 \mathrm{~mm}$, and for the tensile bond strength $50 \times 10 \times 50 \mathrm{~mm}$, respectively, as given in Figure 1.

2.3. Chemistry of $\mathrm{MgO}$ Based Cement. The X-ray diffraction (XRD) analysis was used to characterize hydration products in MPC paste. After 28 days of curing, the paste specimen was dried in the oven at $50^{\circ} \mathrm{C}$ for 48 hours to get rid of the pore water. Then the powder sample was obtained by $\mathrm{X}$-ray diffraction (XRD) analysis, which was conducted by a device D/MAX RINT 2000 with an analyzing range $(2 \theta)$ : $20-70^{\circ}$; scan rate: $4^{\circ} / \mathrm{min}$; voltage: $40 \mathrm{kV}$; current density: $100 \mathrm{~mA}$; tube target: $\mathrm{Cu}$; and wave length: $1.5405 \AA(\mathrm{Cu} / \mathrm{K}-$ $\alpha 1$, respectively.

2.4. Pore Structure. The mercury intrusion porosimetry (MIP) was used to investigate the pore distribution and pore volume of the MPC mortar. A piece of crushed sample was obtained from the middle of the mortar specimen right after the drying process at $50^{\circ} \mathrm{C}$ for 48 hours. Then the sample was placed in a tube filled with mercury. The obtained sample was initially evacuated to about $50 \mu \mathrm{m}$ mercury and the low pressure was generated up to $0.20 \mathrm{MPa}$ by nitrogen gas. The sample was subsequently imposed by mercury filling pressure ranging from $3.7 \times 10^{-3}$ to $413 \mathrm{MPa}$, so that the mercury intrusion volume was recorded at a corresponding pressure. The pore diameter was derived from the pressure using the Washburn equation as given in

$$
d=\frac{-4 \gamma \cos \theta}{P}
$$




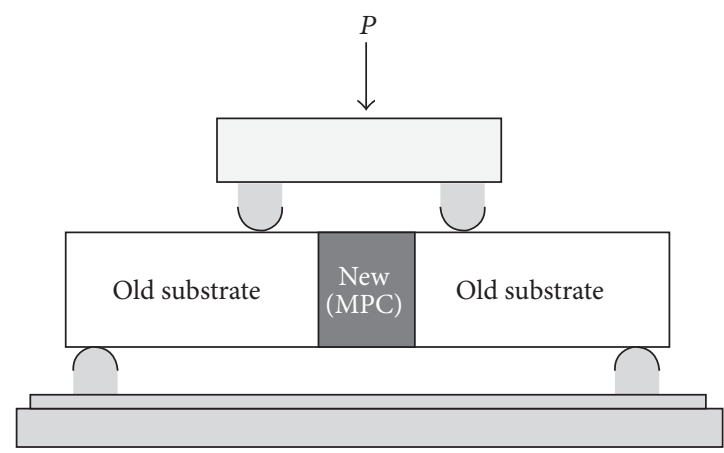

(a) Flexural bond

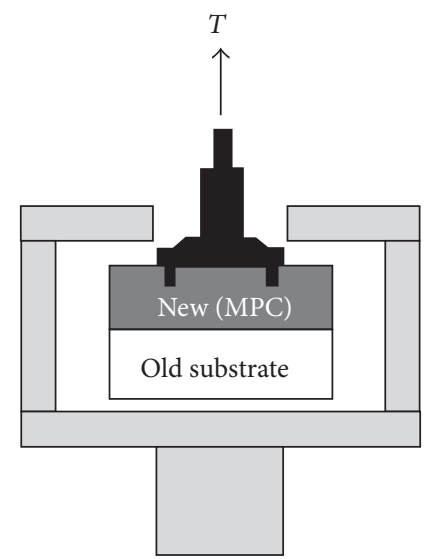

(b) Tensile bond

Figure 1: Schematic for measuring (a) the flexural and (b) tensile bond strength.

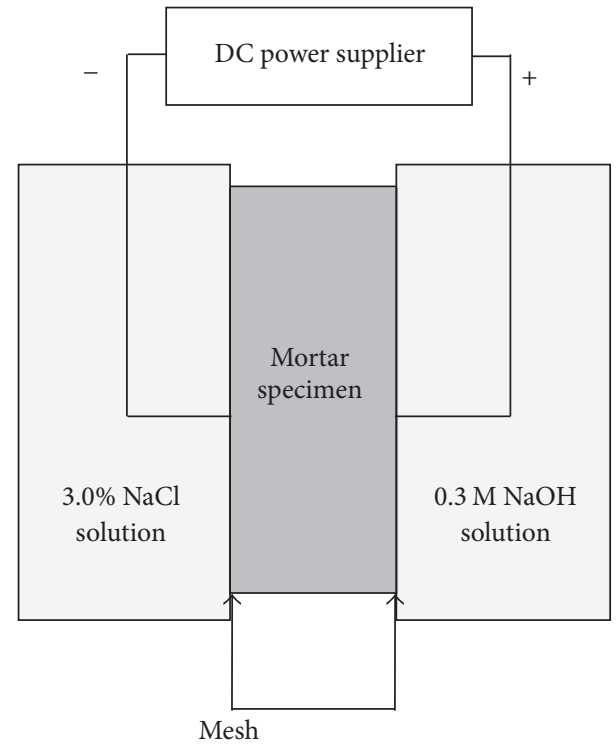

FIGURE 2: Setup for rapid chloride ion penetration test.

where $d$ is the pore diameter $(\mu \mathrm{m}) ; \gamma$ is the surface tension (dynes/cm); $P$ is the pressure (MPa); and $\theta$ is the contact angle $\left(^{\circ}\right)$ in which the present study took this value as $130^{\circ}$.

2.5. Ionic Permeability. The rapid chloride permeability test (RCPT) was used to assess the permeability of MPC concrete compare to that of OPC concrete. This test is based on the standard test method of ASTM C 1202. In this study, however, the mortar specimens were used to minimize the effect of interfacial transition zone (ITZ). A cylinder specimen, $50 \mathrm{~mm}$ in thickness and $100 \mathrm{~mm}$ in diameter, was connected to two chambers: one was filled with $0.3 \mathrm{M}$ of sodium hydroxide and the other chamber $3.0 \%$ of sodium chloride by weight of water to form electrodes. The experimental equipment is shown schematically in Figure 2.
Charged current was calculated by (2) as shown in below, reminding us that if the specimen diameter is other than $95 \mathrm{~mm}$, the charge passed to the established by (3)

$$
\begin{aligned}
Q= & I_{0}+2 \cdot I_{30}+2 \cdot I_{60}+2 \cdot I_{90}+\cdots+2 \cdot I_{300}+2 \\
& \cdot I_{330}+2 \cdot I_{360} \\
Q_{S}^{\prime}= & Q_{X} \times\left(\frac{95}{X}\right)^{2},
\end{aligned}
$$

where $Q$ is total charge passed $(\mathrm{C}), I_{0}$ is initial current immediately after voltage is applied $(\mathrm{A})$, and $I_{t}$ is current at $t$ min. after voltage applied (A), $Q_{S}^{\prime}$ is charge passed through specimen diameter of $95 \mathrm{~mm}(\mathrm{C}), Q_{X}$ is charge passed though specimen diameter of $X \mathrm{~mm}(\mathrm{C})$, and $X$ is diameter of specimens used (mm).

\section{Results and Discussion}

3.1. Mechanical Properties of MPC. The time to set measured by the penetration resistance is given in Figure 3, depending on $\mathrm{M} / \mathrm{P}$ ratio and $\mathrm{B} / \mathrm{M}$ ratio. It is evident that an increase in the $\mathrm{M} / \mathrm{P}$ ratio resulted in an increase in the setting time, irrespective of whether or not borax is admixed. For example, the final setting time at $\mathrm{M} / \mathrm{P}$ ratio of 1 was $15.38 \mathrm{~min}, \mathrm{M} / \mathrm{P}$ of 4 was $16.97 \mathrm{~min}, \mathrm{M} / \mathrm{P}$ of 8 was $18.10 \mathrm{~min}$, and M/P of 16 was $22.61 \mathrm{~min}$, when borax was not admixed. Xu et al. [12] studied properties of MPC mortar and found that the M/P ratio had a crucial impact to the rate of hydration; the lower $\mathrm{M} / \mathrm{P}$ ratio leads to higher hydration heat and this help to have higher chemical reactivity. Thus, the setting time would be presumably related to the purity of magnesia. In the present study, the setting time for the magnesia, of which the purity accounted for $88.5 \%$, ranged within $15-22$ mins, while the setting time was significantly reduced by the higher purity of magnesia (i.e., 94\%) in a previous study [14].

It is clearly seen that the borax increased the setting time at $0.02-0.08$ of $\mathrm{B} / \mathrm{M}$ ratio. Surprisingly, the MPC mortar at 0.10 of $\mathrm{B} / \mathrm{M}$ had the lowest setting time. When the ratio of 


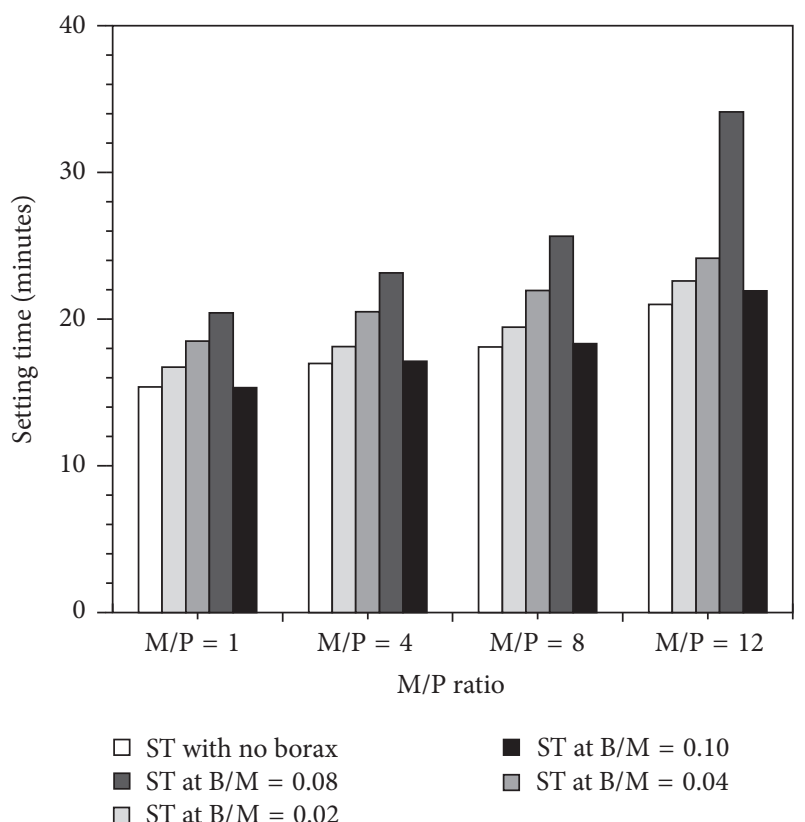

FIgure 3: Time to final set for MPC mortar depending on the M/P and admixing the borax as a retarder.

$\mathrm{M} / \mathrm{P}$ is set to 4 , for example, the time to set at 0.02 of $\mathrm{B} / \mathrm{M}$ was $18.12 \mathrm{~min}$, at 0.04 was $20.51 \mathrm{~min}$, at 0.08 was $23.14 \mathrm{~min}$, and at 0.10 was $17.13 \mathrm{~min}$, respectively. MPC mortar at other $\mathrm{M} / \mathrm{P}$ had the similar results. To increase the setting time, partial replacement with fly ash, ground granulated blastfurnace slag, or aluminate cement would be alternative to chemical admixture [15-19]. Notwithstanding, the time to set seems still very short, ranging from 16.74 to $34.12 \mathrm{~min}$. In in situ testing, it takes usually 2 to 3 hours to cast and patch immediately after mixing, delivering, pumping and other procedures. Thus, the setting time must be further obtained to be reasonable in in situ testing or other techniques; for example, spraying or rolling must be developed.

The compressive strength of MPC mortar was measured at $1,3,12,24$, and 672 hours, as given in Figure 4 . It is seen that an increase in the curing age resulted in an increase in the compressive strength of MPC and control mortar. The compressive strength of MPC is higher than control until 28 days. This is due to high crystallinity of $\operatorname{MgKPO}_{4}\left(\mathrm{H}_{2} \mathrm{O}\right)_{6}$. This is a main hydration product of MPC mortar. The hydration mechanism will be treated in Section 3.2. A development of the compressive strength for MPC specimens was dependent on the $\mathrm{M} / \mathrm{P}$ ratio. For example, the compressive strength of $\mathrm{MPC}$ was $5.47 \mathrm{MPa}$ at 1.0 of $\mathrm{M} / \mathrm{P}$ ratio and $22.8 \mathrm{MPa}$ at 4.0 , the highest strength. Then, the strength was reduced by an increase in the M/P. It may be attributed to the fact that the lower $\mathrm{M} / \mathrm{P}$ ratio leads to having higher hydration heat and this help to have higher chemical reactivity [12].

At 4.0 of $\mathrm{M} / \mathrm{P}$, the effect of borax on the compressive strength for MPC mortar was examined after 24 hours curing. Simultaneously, the setting time for borax was measured, as given in Figure 5. It is clearly seen that an increase in the $\mathrm{B} / \mathrm{M}$ ratio resulted in a decrease in the compressive strength.

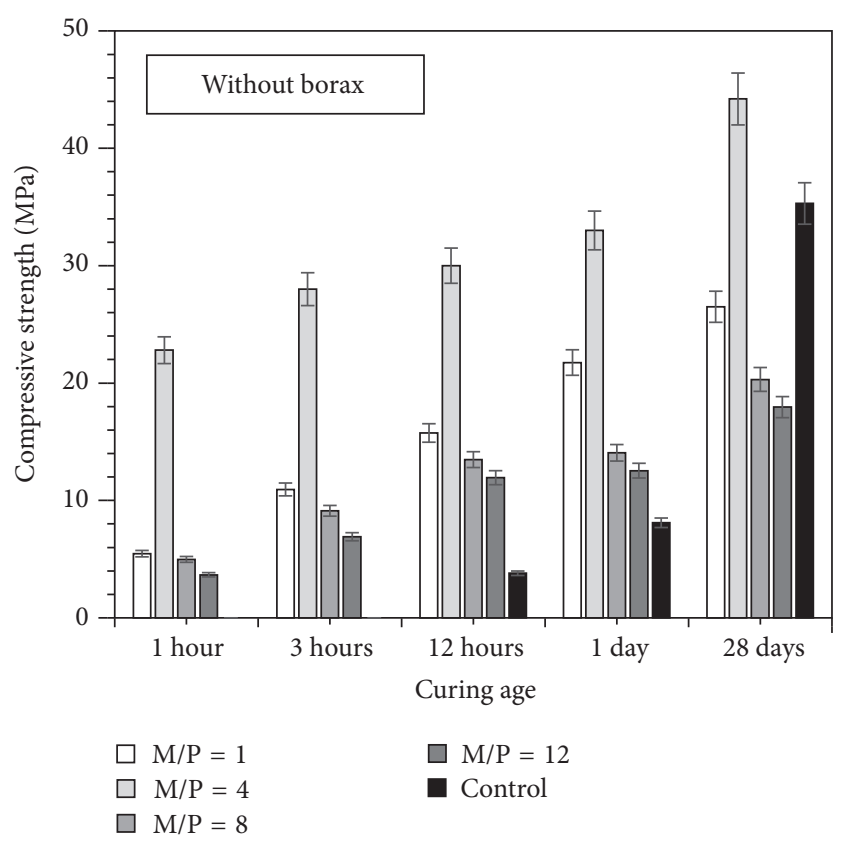

Figure 4: Development of compressive strength for MPC and control mortar specimens depending on the $\mathrm{M} / \mathrm{P}$ ratio and curing age without borax.

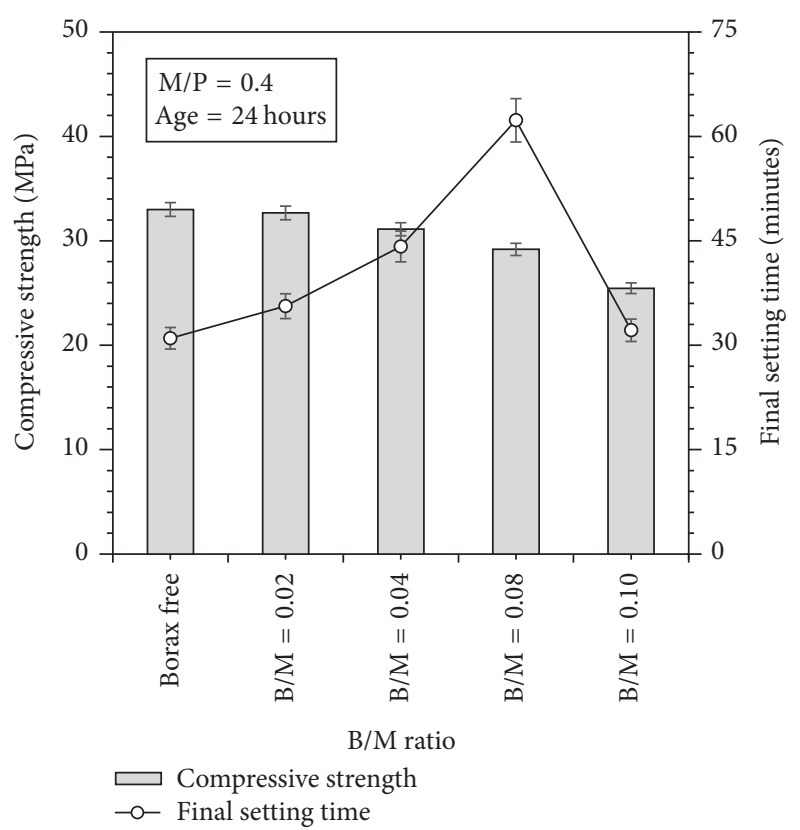

FIGURE 5: Development of compressive strength and final setting time for MPC mortar admixed with/without borax (B/M of ranging 0 to 0.10 ) at M/P of 4 and age of 24 hours.

For example, the compressive strength of MPC with no borax was $33.00 \mathrm{MPa}, 32.67 \mathrm{MPa}$ at 0.02 of $\mathrm{B} / \mathrm{M}, 31.11 \mathrm{MPa}$ at 0.04 of $\mathrm{B} / \mathrm{M}, 29.18 \mathrm{MPa}$ at 0.08 of $\mathrm{B} / \mathrm{M}$, and $25.46 \mathrm{MPa}$ at 0.10 of $\mathrm{B} / \mathrm{M}$, respectively. However, the borax did not always reduce the rate of hardening process. Until 0.08 of $\mathrm{B} / \mathrm{M}$, the setting time was increased, but beyond this level of borax, the setting time 
was adversely reduced. Thus, a cautious care must be taken in using the borax to increase the setting time.

The flexural and tensile bond strength measured at 28 days is given in Figure 6. The MPC mortar always had higher bond strength both tensile and flexural strength, compared to control mortar patching. For tensile bond, the MPC mortar produced about $1.9 \mathrm{MPa}$ while control mortar achieved 1.5 MPa. The higher level of flexural bon strength was also observed in MPC mortar. The flexural bond strength of MPC was $1.7 \mathrm{MPa}$ while control mortar achieved only 1.2 MPa. Li et al. [17] also investigated the tensile and flexural bond strength found using other type of phosphate such as diammonium phosphate $\left(\left(\mathrm{NH}_{4}\right)_{2} \mathrm{HPO}_{4}\right)$ and disodium hydrogen phosphate $\left(\mathrm{Na}_{2} \mathrm{HPO}_{4} \cdot 12 \mathrm{H}_{2} \mathrm{O}\right)$ and had almost doubled the higher strength in flexural strength when diammonium phosphate was used, which does not, however, seem suitable due to its environmental issues.

3.2. Hydration Products. The $\mathrm{XRD}$ curve of representative MPC paste (M/P was 4.0 with no borax) after 28 days of curing was obtained as given in Figure 7. According to the diffraction peaks, there is a main phase of crystal product that was found in XRD pattern. $\mathrm{MgKPO}_{4} \cdot 6 \mathrm{H}_{2} \mathrm{O}$ is the main hydration product of MPC paste. Another phase was unreacted magnesia $(\mathrm{MgO})$, which would subsequently react further and could have increased strength. In mechanism of hydration of MPC, the presence of struvite of potassium would be key factor in the reaction products, as struvite can be present in both crystalline and amorphous form. The reaction process is given by following equations [20]:

$$
\begin{aligned}
& \mathrm{KH}_{2} \mathrm{PO}_{4} \longrightarrow \mathrm{K}^{+}+\mathrm{H}_{2} \mathrm{PO}_{4}^{-} \\
& \mathrm{KH}_{2} \mathrm{PO}_{4} \longrightarrow \mathrm{K}^{+}+\mathrm{HPO}_{4}{ }^{2-}+\mathrm{H}^{+} \\
& \mathrm{KH}_{2} \mathrm{PO}_{4} \longrightarrow \mathrm{K}^{+}+\mathrm{PO}_{4}{ }^{3-}+2 \mathrm{H}^{+} \\
& \mathrm{MgO}+\mathrm{H}_{2} \mathrm{O} \longrightarrow \mathrm{MgOH}^{+}+\mathrm{OH}^{-} \\
& \mathrm{MgOH}^{+}+2 \mathrm{H}_{2} \mathrm{O} \longrightarrow \mathrm{Mg}(\mathrm{OH})_{2}+\mathrm{H}_{3} \mathrm{O}^{+} \\
& \mathrm{Mg}(\mathrm{OH})_{2} \longrightarrow \mathrm{Mg}^{2+}+2 \mathrm{OH}^{-} \\
& \mathrm{Mg}^{2+}+6 \mathrm{H}_{2} \mathrm{O} \longrightarrow \mathrm{Mg}\left(\mathrm{H}_{2} \mathrm{O}\right)_{6}{ }^{2+} \mathrm{K}^{+}+\mathrm{Mg}\left(\mathrm{H}_{2} \mathrm{O}\right)_{6}{ }^{2+}+\mathrm{PO}_{4}{ }^{3-} \longrightarrow \mathrm{MgKPO}_{4} \cdot 6 \mathrm{H}_{2} \mathrm{O} \text { (Final hydration form) }
\end{aligned}
$$

3.3. Pore Structure and Ionic Permeability. The pore volume of MPC mortar measured by the mercury intrusion porosimetry is illustrated in Figure 8. It is seen that total cumulative pore volume in the MPC mortar was varied with M/P ratio. In fact, an increase in the $\mathrm{M} / \mathrm{P}$ ratio resulted in an increase in the pore volume. For example, the total cumulative pore volume of MPC at 1.0 of M/P was $0.0759 \mathrm{~mL} / \mathrm{g}, 0.0831 \mathrm{~mL} / \mathrm{g}$ at $4.0,0.1107 \mathrm{~mL} / \mathrm{g}$ at 8.0 , and $0.1382 \mathrm{~mL} / \mathrm{g}$ at 12.0 , corresponding to $13.9,15.5,20.5$, and $25.5 \%$ in volume, respectively. The influence of $\mathrm{M} / \mathrm{P}$ on the porosity may be attributed to pore formation in the process of hydration. In fact, an increase in $\mathrm{M} / \mathrm{P}$ (i.e., increased magnesia) accompanied an increase in the capillary pore, leading to the entire porosity.

The pore volume and distribution of MPC and control mortar measured by the mercury intrusion porosimetry are illustrated in Figure 9. It is seen that total pore volume in the MPC mortar accounted for $0.074 \mathrm{~mL} / \mathrm{g}$, corresponding to $15.5 \%$ in porosity. In fact, this level of porosity is slightly smaller than for OPC mortar ranging within 17-21\%. Due to its smaller porosity, MPC mortar gained higher compressive strength in present study. This may be due to high crystalline structure of $\mathrm{MgKPO}_{4} \cdot 6 \mathrm{H}_{2} \mathrm{O}$ compared to hydration product such as $\mathrm{C}-\mathrm{S}-\mathrm{H}$ in OPC matrix. It can be said that the pore structure of the MPC benefits in raising the durability against degrading environments. For example, the peak intensity at pore diameter for MPC mortar was in the range of 200 to 4,000 $\mathrm{nm}$, entrained air void, imposing the higher resistance to freeze and thaw. Entrained air void buffers the expansion of freezing in pore water to reduce internal stress. In OPC mortar, the peak intensity at pore diameter was in the range of 0.04 to $2 \mathrm{~nm}$, as being equivalent to capillary pore which is related to the ionic transport properties. Moreover, the capillary pores can make internetwork for ionic transport.

The current passed through the MPC and OPC cells is plotted with time in Figure 10, together with charges passed for the duration. The ionic permeability of the OPC concrete specimen had the higher current and charge, accounting for $4112.0 \mathrm{C}$, while MPC concrete specimen was $3238.4 \mathrm{C}$. The MPC concrete produced the higher resistance to ionic transport. A low charge passed in MPC concrete may result from the pore distribution. In OPC mortar, capillary pores mostly occupy the pore constitute, which could form an internetwork for ionic transport. However, in MPC, entrained air void is mainly constituted in the pore structure. According to the guided values for the ionic penetration, both concrete specimens were marked in moderate range as shown in Table 3, presumably due to absence of grave in mix.

\section{Conclusion}

In this study, the possibility of MPC mortar for patching in the pavement was assessed by mechanical properties and chemical analysis. The test covers the compressive strength, bond strength to old substrate, and setting time. 


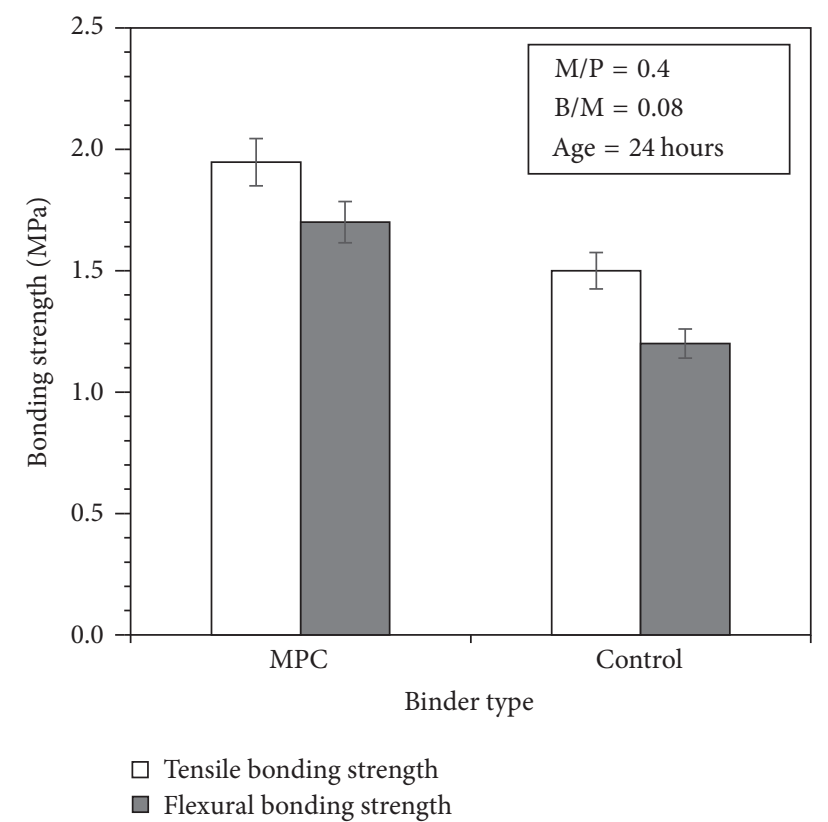

FIgURE 6: Tensile and flexural bond strength of MPC mortar to old substrate, compared to control mortar patching.

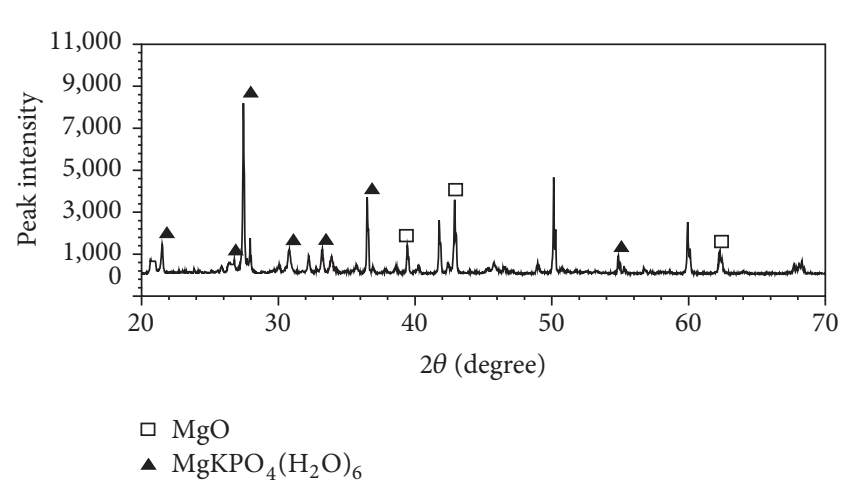

FIGURE 7: X-ray diffraction patterns of MPC paste without borax at $\mathrm{M} / \mathrm{P}$ ratio of 4 and age of 28 days.

TABLE 3: Chloride ion penetrability based on charge passed for concrete specimen (ASTM C 1202-91).

\begin{tabular}{lc}
\hline Charge passed (Coulombs) & Chloride ion penetrability \\
\hline$>4000$ & High \\
$2000-4000$ & Moderate \\
$1000-2000$ & Low \\
$100-1000$ & Very low \\
$<100$ & Negligible \\
\hline
\end{tabular}

Simultaneously, its hydration product and ionic transport were examined. To verify the ratio of $\mathrm{M} / \mathrm{P}$, the variation in the $\mathrm{M} / \mathrm{P}$ was considered. The conclusions derived from the experimental works are as follows:

(1) The setting time measured by the penetration resistance using vicat needles to fresh mortar ranged from 15.4 to $34.1 \mathrm{~min}$, depending on the $\mathrm{M} / \mathrm{P}$ ratio and $\mathrm{B} / \mathrm{M}$

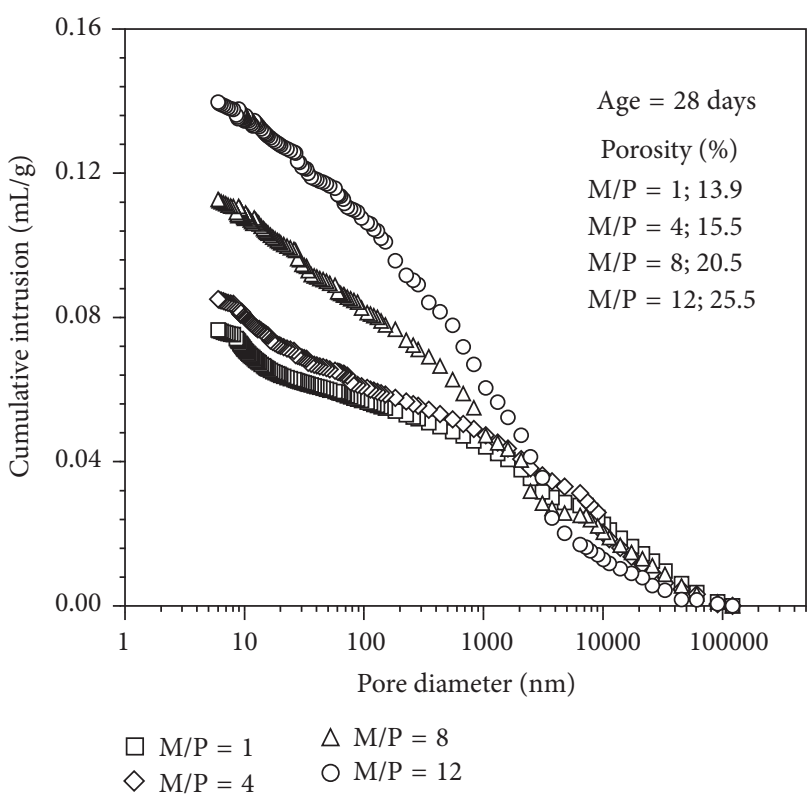

FIGURE 8: Cumulative intrusion of MPC mortar depends on the M/P ratio.

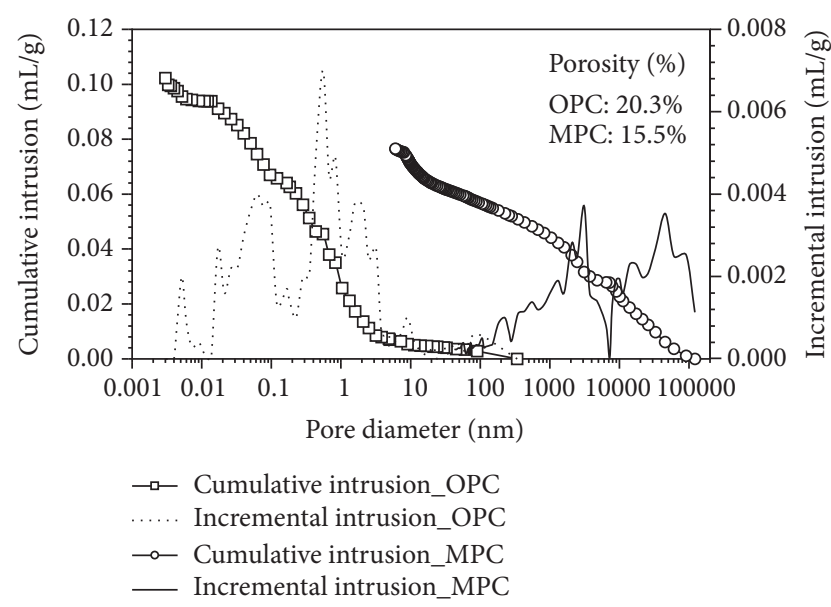

FIGURE 9: The cumulative and incremental intrusion of MPC at M/P of 4 and control mortar at 24 days.

ratio. An increase in the $\mathrm{M} / \mathrm{P}$ ratio resulted in an increase in the setting time. For borax, the setting time could be increased up to at 0.08 of $\mathrm{B} / \mathrm{M}$, but the setting time was adversely reduced at exceeding this level.

(2) A very rapid development of the compressive strength was achieved within several hours. The strength exceeded 22.8 MPa after 1 hour, 28.0 MPa after 3 hours, and $33.0 \mathrm{MPa}$ after 24 hours at 4.0 of the M/P ratio. However, the compressive strength for MPC mortar was lowered by addition of borax.

(3) The tensile and flexural bond strength to old substrate accounted for 1.9 and $1.7 \mathrm{MPa}$, respectively, while the bond of OPC mortar patching was about 1.5 and 1.2 MPa, respectively. 


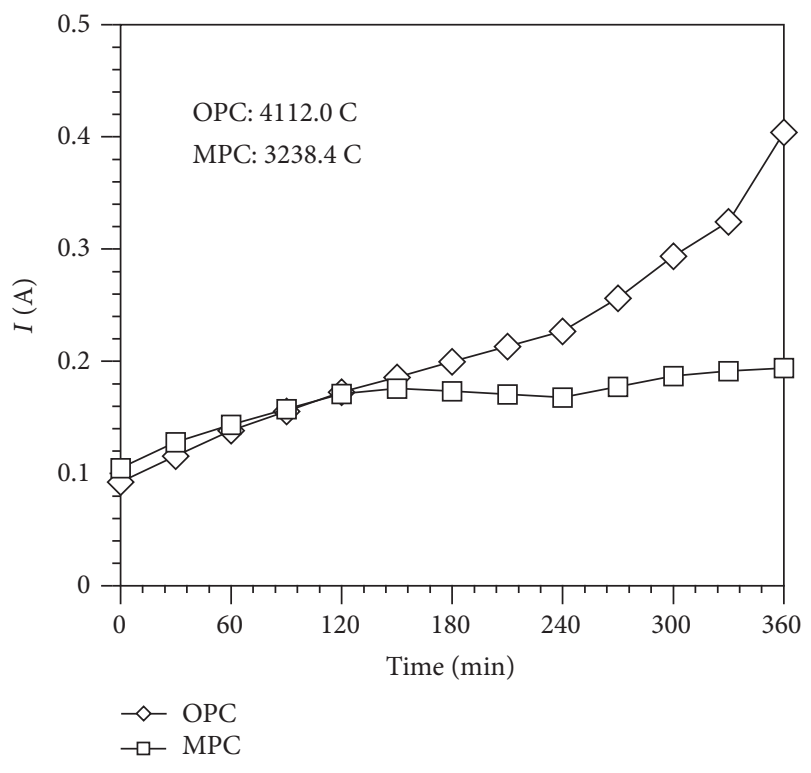

Figure 10: Charged current with time depending on binder type.

(4) The porosity of MPC measured by the mercury intrusion porosimetry was in the range of 13.9 to $25.5 \%$, depending on the M/P ratio. An increase in the $\mathrm{M} / \mathrm{P}$ ratio resulted in an increase in the porosity, presumably due to hydration degree of magnesia. In particular, the entrained air void was mostly occupied the pore range of the MPC.

\section{Competing Interests}

The authors declare that they have no competing interests.

\section{Acknowledgments}

This research was supported by a grant (13IFIP-B06700801) from Industrial Facilities \& Infrastructure Research Program funded by the Ministry of Land, Infrastructure and Transport of Korean government.

\section{References}

[1] M. A. Frabizzio and N. J. Buch, "Performance of transverse cracking in jointed concrete pavements," Journal of Performance of Constructed Facilities, vol. 13, no. 4, pp. 172-180, 1999.

[2] K. Y. Ann, J. H. Ahn, and J. S. Ryou, "The importance of chloride content at the concrete surface in assessing the time to corrosion of steel in concrete structures," Construction and Building Materials, vol. 23, no. 1, pp. 239-245, 2009.

[3] R. Robinson, U. Danielson, and M. Snaith, Road Maintenance Management: Concepts and Systems, Macmillan, 1998.

[4] F. Giussani and F. Mola, "Durable concrete pavements: the reconstruction of runway head 36R of Milano Linate International Airport," Construction and Building Materials, vol. 34, pp. 352-361, 2012.

[5] R. Hicks, J. Moulthrop, and J. Daleiden, "Selecting a preventive maintenance treatment for flexible pavements," Foundation for Pavement Preservation, Publication no. FHWA-IF-00-027, 2000.

[6] G. Rada, R. Perera, V. Prabhakar, and L. Wiser, "Relating ride quality and structural adequacy for pavement rehabilitation and management decisions," Transportation Research Record, vol. 2304, pp. 28-36, 2012.

[7] T. Sugama and L. E. Kukacka, "Magnesium monophosphate cements derived from diammonium phosphate solutions," Cement and Concrete Research, vol. 13, no. 3, pp. 407-416, 1983.

[8] S. S. Seehra, S. Gupta, and S. Kumar, "Rapid setting magnesium phosphate cement for quick repair of concrete pavementscharacterisation and durability aspects," Cement and Concrete Research, vol. 23, no. 2, pp. 254-266, 1993.

[9] Q. Yang, B. Zhu, and X. Wu, "Characteristics and durability test of magnesium phosphate cement-based material for rapid repair of concrete," Materials and Structures, vol. 33, no. 228, pp. 229-234, 2000.

[10] B. E. I. Abdelrazig, J. H. Sharp, and B. El-Jazairi, “The chemical composition of mortars made from magnesia-phosphate cement," Cement and Concrete Research, vol. 18, no. 3, pp. 415425, 1988.

[11] Q. Yang, S. Zhang, and X. Wu, "Deicer-scaling resistance of phosphate cement-based binder for rapid repair of concrete," Cement and Concrete Research, vol. 32, no. 1, pp. 165-168, 2002.

[12] B. Xu, H. Ma, and Z. Li, "Influence of magnesia-to-phosphate molar ratio on microstructures, mechanical properties and thermal conductivity of magnesium potassium phosphate cement paste with large water-to-solid ratio," Cement and Concrete Research, vol. 68, pp. 1-9, 2015.

[13] F. Qiao, C. K. Chau, and Z. Li, "Property evaluation of magnesium phosphate cement mortar as patch repair material," Construction and Building Materials, vol. 24, no. 5, pp. 695-700, 2010.

[14] Q. Yang and X. Wu, "Factors influencing properties of phosphate cement-based binder for rapid repair of concrete," Cement and Concrete Research, vol. 29, no. 3, pp. 389-396, 1999.

[15] J. Li, G. Xu, Y. Chen, and G. Liu, "Multiple scaling investigation of magnesium phosphate cement modified by emulsified asphalt for rapid repair of asphalt mixture pavement," Construction and Building Materials, vol. 69, pp. 346-350, 2014.

[16] H. Lahalle, C. C. D. Coumes, A. Mesbah et al., "Investigation of magnesium phosphate cement hydration in diluted suspension and its retardation by boric acid," Cement and Concrete Research, vol. 87, pp. 77-86, 2016.

[17] J. Li, W. Zhang, and Y. Cao, "Laboratory evaluation of magnesium phosphate cement paste and mortar for rapid repair of cement concrete pavement," Construction and Building Materials, vol. 58, pp. 122-128, 2014.

[18] N. Liu and B. Chen, "Experimental research on magnesium phosphate cements containing alumina," Construction and Building Materials, vol. 121, pp. 354-360, 2016.

[19] Y. Li and B. Chen, "Factors that affect the properties of magnesium phosphate cement," Construction and Building Materials, vol. 47, pp. 977-983, 2013.

[20] Z. Ding, B. Dong, F. Xing, N. Han, and Z. Li, "Cementing mechanism of potassium phosphate based magnesium phosphate cement," Ceramics International, vol. 38, no. 8, pp. 6281-6288, 2012. 

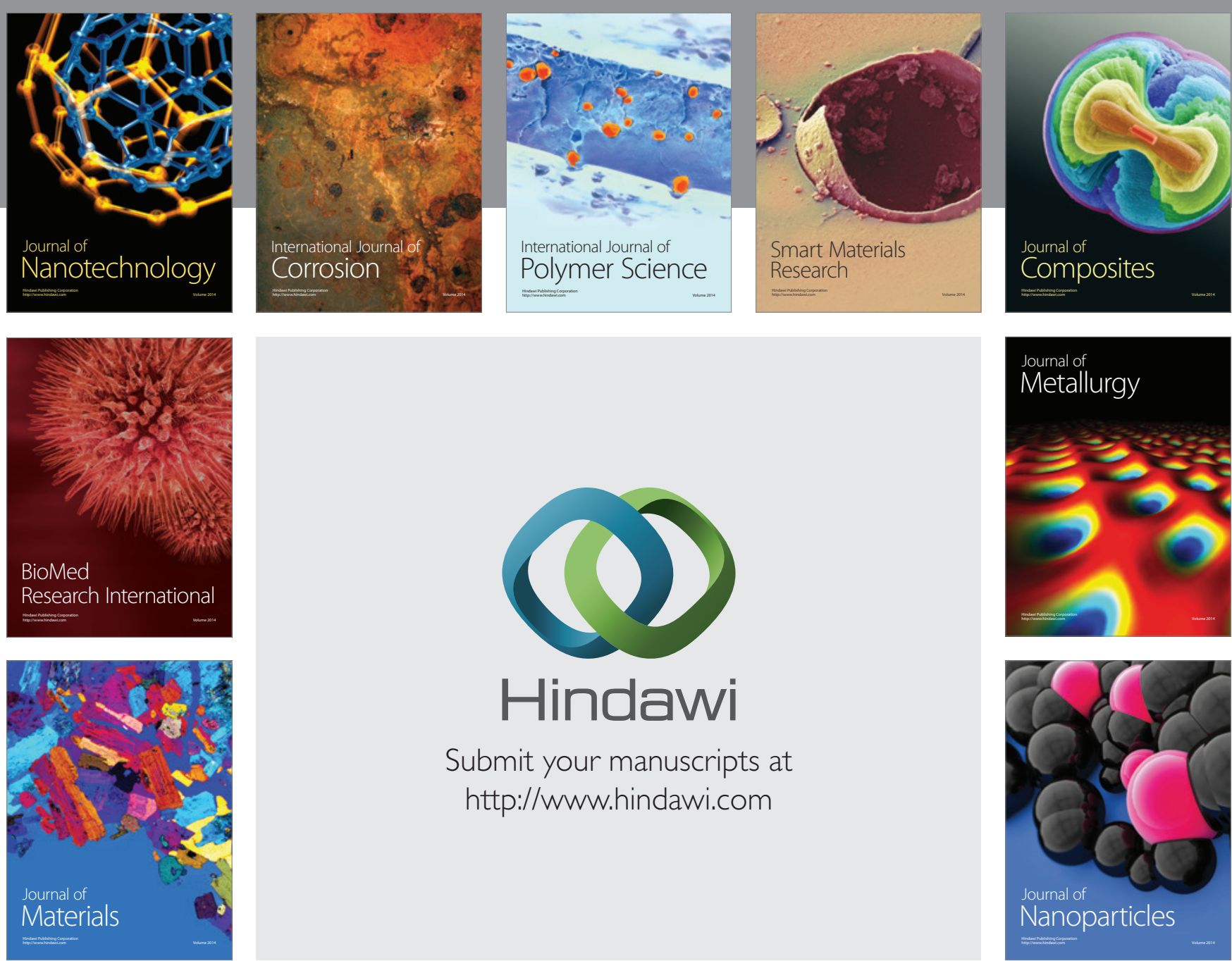

\section{Hindawi}

Submit your manuscripts at

http://www.hindawi.com

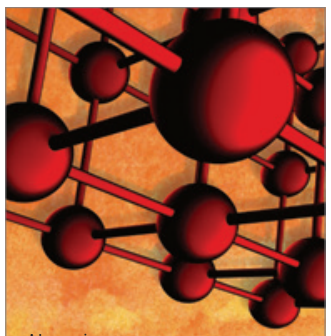

Materials Science and Engineering
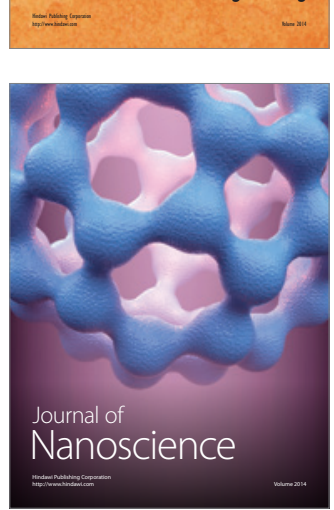
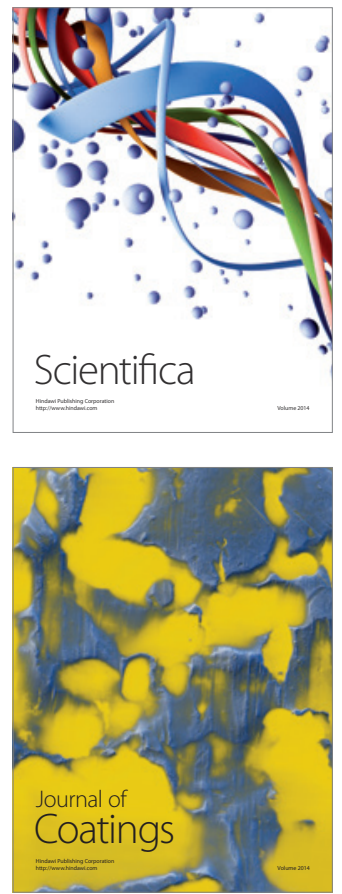
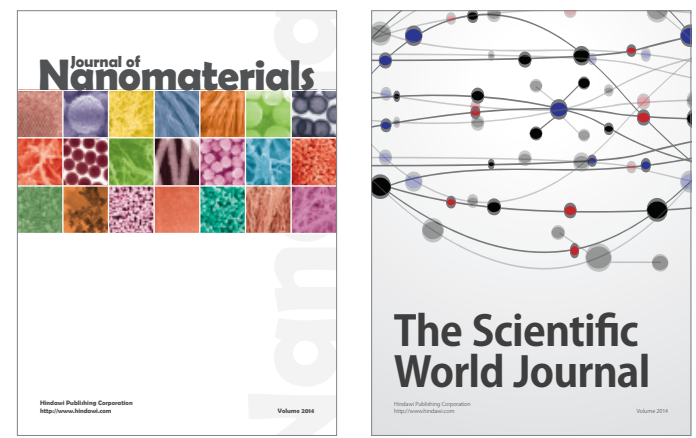

The Scientific World Journal
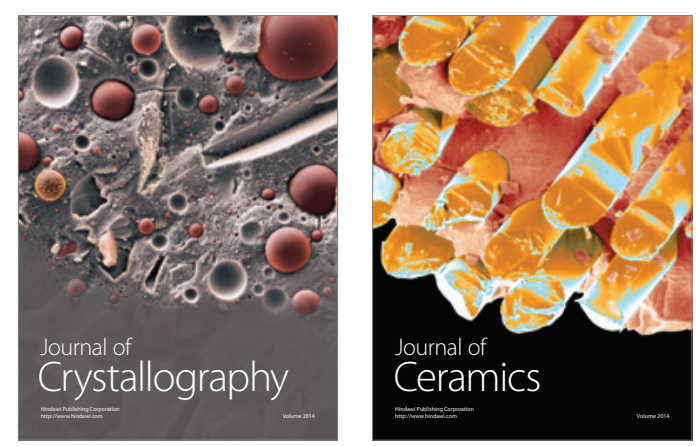
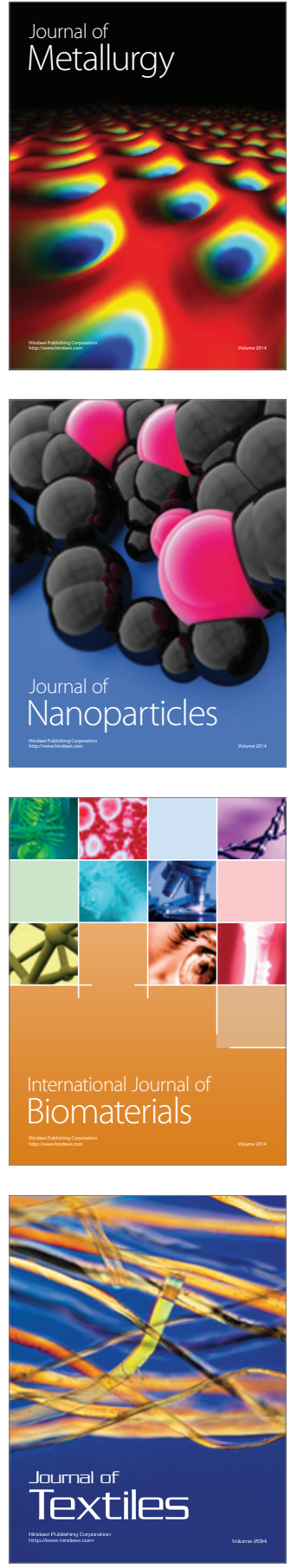